\title{
Safety and Efficacy of Combination Therapy with Insulin Glargine and Oral Hypoglycaemic Agents Including DPP-4 Inhibitors in Japanese T2DM Patients: ALOHA 2 Study, a Post-Marketing Surveillance for Lantus ${ }^{\circledR}$
}

\author{
Masayuki Kobayashi, Shoko Tsukube*, Yukio Ikeda, Yujin Shuto \\ Sanofi K.K., Tokyo, Japan \\ Email: 'Shoko.Tsukube@sanofi.com
}

Received 4 August 2014; revised 3 September 2014; accepted 1 October 2014

Copyright (C) 2014 by authors and Scientific Research Publishing Inc.

This work is licensed under the Creative Commons Attribution International License (CC BY). http://creativecommons.org/licenses/by/4.0/

(c) (7) Open Access

\section{Abstract}

Aims: In the Add-on Lantus ${ }^{\circledR}$ to Oral Hypoglycaemic Agents 2 (ALOHA 2) Study in Japanese adults with type 2 diabetes mellitus (T2DM), data on the safety and efficacy of combination therapy with insulin glargine (Lantus ${ }^{\circledR}$ ) and oral anti-hyperglycaemic drugs (OADs) including dipeptidyl peptidase-4 (DPP-4) inhibitors in a real-life setting were collected and analyzed. Methods: This postmarketing surveillance was a prospective, observational, 24-week study that complied with the pharmaceutical affairs law and the ministerial ordinance of "Good Post-Marketing Study Practice (GPSP)" in Japan. Safety, efficacy and patient-reported outcomes (PROs); patients' satisfaction with treatment (DTSQs and DTSQc) and patients' self-reported health (EQ-5D and EQ-VAS) of combination therapy of insulin glargine and OADs were evaluated. Results: A total of 2,630 patients were enrolled. Of the 2,602 patients in the safety analysis population, 161 patients experienced 175 cases of adverse drug reactions, and the major adverse drug reaction was hypoglycaemia (140 patients, $5.38 \%)$. Out of those with hypoglycaemia, 11 patients $(0.42 \%)$ had severe hypoglycaemia and the incidence rate (episodes per patient-year) was 0.019. Basal supported oral therapy (BOT) with insulin glargine substantially reduced the HbA1c, FPG and 2 hour-PPG levels for 24 weeks by $-1.61 \%,-54.4 \mathrm{mg} / \mathrm{dL}$ and $-74.5 \mathrm{mg} / \mathrm{dL}$ respectively. The mean weight was increased, however the change was $+0.50 \mathrm{~kg}$. In addition, the treatment satisfaction scores of DTSQs (mean treatment satisfaction score increased 3.6 from baseline to last observation) and DTSQc, EQ-5D index scores and EQ-VAS scores were significantly improved. Conclusion: Insulin glargine and OADs combina${ }^{*}$ Corresponding author.

How to cite this paper: Kobayashi, M., et al. (2014) Safety and Efficacy of Combination Therapy with Insulin Glargine and Oral Hypoglycaemic Agents Including DPP-4 Inhibitors in Japanese T2DM Patients: ALOHA 2 Study, a Post-Marketing Surveillance for Lantus ${ }^{\circledR}$. Journal of Diabetes Mellitus, 4, 273-289. http://dx.doi.org/10.4236/jdm.2014.44039 
tion therapy was suggested to be effective and well tolerated. Patients' satisfaction with treatment and their self-reported health improved in spite of the addition of injections to oral agents. The combination therapy of insulin glargine and OADs including DPP-4 inhibitors is likely to be considered an important therapeutic option in the diabetic patients.

\section{Keywords}

\section{ALOHA 2, Insulin Glargine, Patient-Reported Outcomes, Post-Marketing Surveillance Study, Type 2 Diabetes}

\section{Introduction}

A basal supported oral therapy (BOT) with insulin products from the early stage in patients with inadequate glycaemic control on oral anti-hyperglycaemic drugs (OADs) has rapidly become prevalent in the treatment of T2DM [1].

Insulin glargine (Lantus ${ }^{\circledR}$ ) is a long-acting soluble insulin analog [2]. After its subcutaneous injection, insulin glargine does not cause a pronounced plasma concentration peak because of its gradual absorption, and its stable glucose-lowering action is maintained for approximately one day [3] [4]. Insulin glargine is basal insulin that is frequently used for not only intensive insulin therapy but also BOT. In particular, the clinical usefulness of BOT with insulin glargine has been reported in clinical studies [5]-[7]. The large-scale ALOHA Study, a post-marketing surveillance study was conducted in Japanese patients with T2DM to investigate the safety and efficacy of the combination therapy with insulin glargine and OADs in Japan between 2007 and 2009 [8]-[11]. The results of the ALOHA Study indicate that the combination therapy was well tolerated and had a good glycaemic control.

Following the recent approval of 6 DPP-4 inhibitors in Japan, they are used to treat T2DM as OADs by improving glycaemic control, while being unlikely to cause hypoglycaemia [12] [13]. In addition, these DPP-4 inhibitors can be used in combination with insulin products in Japan, and these combination therapies significantly reduced HbA1c, FPG and PPG levels [14] [15]. It has reported that the inhibition of PPG level reduced the cardiovascular events, PPG inhibition is considered to be an important factor for the treatment of diabetes [16].

Patient-reported outcomes (PROs) as the patients' satisfaction with treatment or their self-reported health were also important factors for therapeutic options since satisfaction and flexibility of dosing could result in a better therapy from the viewpoint of adherence. The assessment questionnaires for them were developed as Diabetes Treatment Satisfaction Questionnaires (status version: DTSQs and change version: DTSQc) or EuroQOL fivedimensions questionnaire (EQ-5D) [17]-[19]. DTSQs, DTSQc and EQ-5D were used for the evaluation of satisfaction with treatment or self-reported health in patients with diabetes [20]-[24].

In the present ALOHA 2 Study (a post-marketing surveillance study), the safety, efficacy and PROs of the combination therapy with insulin glargine and OADs including DPP-4 inhibitors in a real-life setting were surveyed in Japanese T2DM patients.

\section{Methods}

\subsection{Subjects}

A total of 2630 patients were enrolled from 619 hospitals and clinics in Japan between January and November 2012 and observed for 24 weeks. Insulin glargine naïve T2DM patients treated with OADs who started BOT with insulin glargine were enrolled if aged $\geq 20$ years, with HbA1c value of $\geq 6.5$ during previous 4 weeks, and provided informed consent. The patients with basal-bolus regimen \pm OADs and basal-only regimen were not included by the protocol.

\subsection{Study Design}

This post-marketing surveillance was a prospective, observational, 24-week study that complied with the pharmaceutical affairs law and the ministerial ordinance of "Good Post-Marketing Study Practice (GPSP)" in Japan 
and was conducted after a contract was signed with each medical institution participating in the survey. All treatment decisions were made by the attending physicians, and data regarding the administration times and doses (units/day) of insulin glargine including compliance as well as types and doses of OADs used in combination treatment were collected.

\subsection{Safety}

To evaluate safety, adverse drug reactions and abnormal variations in laboratory test parameters (hematology test, clinical biochemical test, urine analysis and vital signs) were collected. When adverse events were observed, attending physicians assessed the events in terms of type, seriousness, outcomes, and causal relationship with insulin glargine. The presence or absence of hypoglycaemia, an accompanying symptom of hypoglycaemia, the presence or absence of care assistance, the presence or absence of nocturnal hypoglycaemia and the plasma glucose level at the incidence of hypoglycaemia were surveyed. All events besides those determined to have "no causal relationship with insulin glargine” were considered as adverse drug reactions. Adverse drug reactions were classified according to the Medical Dictionary for Regulatory Activities/Japanese version (MedDRA/J) 16.0. Hypoglycaemia was categorized for the analysis as follows:

1) Severe hypoglycaemia: serious or required assistance of another person;

2) Documented symptomatic hypoglycaemia: typical symptoms of hypoglycaemia accompanied by plasma glucose concentration $\leq 70 \mathrm{mg} / \mathrm{dL}$;

3) Nocturnal hypoglycaemia: reported as nocturnal hypoglycaemia by the attending physicians.

\subsection{Efficacy}

HbA1c, FPG and 2 hour-PPG levels were collected before treatment to the endpoint, the values determined by LOCF method. HbA1c data were collected as JDS values or NGSP values. If the data were JDS values, they were converted to NGSP equivalent values by the following conversion formula: HbA1c $(\mathrm{NGSP})=1.02 \times \mathrm{HbA1c}$ (JDS) $+0.25 \%[25]$.

At the end of observation period, attending physicians classified the compliance status (good compliance $\geq$ $75 \%$, poor compliance $\geq 50 \%$, $<75 \%$ and noncompliance $<50 \%$ ) of therapies including insulin glargine treatment, exercise and diet therapies.

\subsection{PROs, Patients' Satisfaction with Treatment and Patients' Self-Reported Health}

PROs were evaluated before, during treatment (Weeks 6-14), and at the end of the observation using DTSQs, EQ-5D and EQ-VAS scores, and DTSQc was evaluated at the end of the observation only. The patients' satisfaction with treatment was evaluated using DTSQs and DTSQc, and their self-reported health was evaluated using EQ-5D and EQ-VAS [26]-[31]. Patients placed the completed questionnaires in a sealed envelope and handed them to attending physicians, so that the physicians were blinded to the patients' responses.

In the DTSQs questionnaire, Questions 1 and 4-8 concern the patients' satisfaction with treatment, these were concerned with general satisfaction with treatment convenience, flexibility, satisfaction with own understanding of their diabetes, likelihood of their recommending a treatment to others and willingness to continue present treatment. The scores from these 6 questions were summed to a treatment satisfaction score, ranging from 0 (most dissatisfied) to 36 (most satisfied). Questions 2 and 3 are concerned the perceived frequency of hyperglycaemia and hypoglycaemia. Question 2 (hyperglycaemia) and Question 3 (hypoglycaemia) were evaluated separately, questions are scored from 0 (not at all) to 6 (most of the time).

DTSQc was completed at endpoint. The DTSQc uses the same questions as the DTSQs but the instructions ask respondents to compare their satisfaction with their current treatment with their satisfaction with the treatment used before the study began. Response options range from 3 (i.e. much more satisfied now) to -3 (i.e. much less satisfied now) and responses to Questions 1 and 4-8 are again summed, to produce change in satisfaction scores ranging from 18 to -18 with a midpoint of zero representing no change. P-value of satisfaction score, hyperglycaemia score and hypoglycaemia score were estimated by comparing the DTSQc value obtained against zero which is the response that would indicate no change.

The EQ-5D consists of 2 sections which involved a 5-item method (EQ-5D index score) to assess health status on 5 dimensions (mobility, self-care, usual activities, pain/discomfort and anxiety/depression) and the visual 
assessment method (EQ-VAS, 0 - 100 points). This questionnaire was conducted to assess the outcomes on health condition before and during treatment (Weeks 6-14) and at the endpoint.

\subsection{Analysis Methods}

The Fisher's exact test or Cochran-Armitage test was used for the analysis of risk factors of hypoglycaemia. The mean differences in HbA1c, FPG, 2 hour-PPG levels and weight from the baseline to the endpoint were analyzed using the paired t-test, and the changes of DTSQs, EQ-5D index and EQ-VAS scores were evaluated using the Wilcoxon signed-rank test.

\section{Results}

\subsection{Patient Disposition}

A total of 2630 patients with T2DM from 619 institutions in Japan were enrolled (Figure 1), of whom 28 patients were excluded for the analysis because of not returning a case report form (CRF) or having not received insulin glargine or having no data after initial prescription of insulin glargine.

The remaining 2602 patients who received insulin glargine were included in the safety analysis. Of them, patients with protocol deviations such as those being treated with other insulin before the observation, those not being treated with BOT during the observation (treated with basal-bolus therapy or not treated with OADs during the observation), those without data of HbA1c level in the 4 weeks prior to the initiation of insulin glargine and a few others were excluded from the efficacy analysis population.

The efficacy analysis population included 1629 patients who were treated with OADs without insulin before the enrollment and started BOT with insulin glargine. PROs results were analyzed in the efficacy analysis population.

\subsection{Patient Characteristics}

The baseline characteristics of the safety analysis population and efficacy analysis population are shown in Table 1 . In the safety population of $2602,60.2 \%$ were male and the mean age was 62.6 years. The weight and

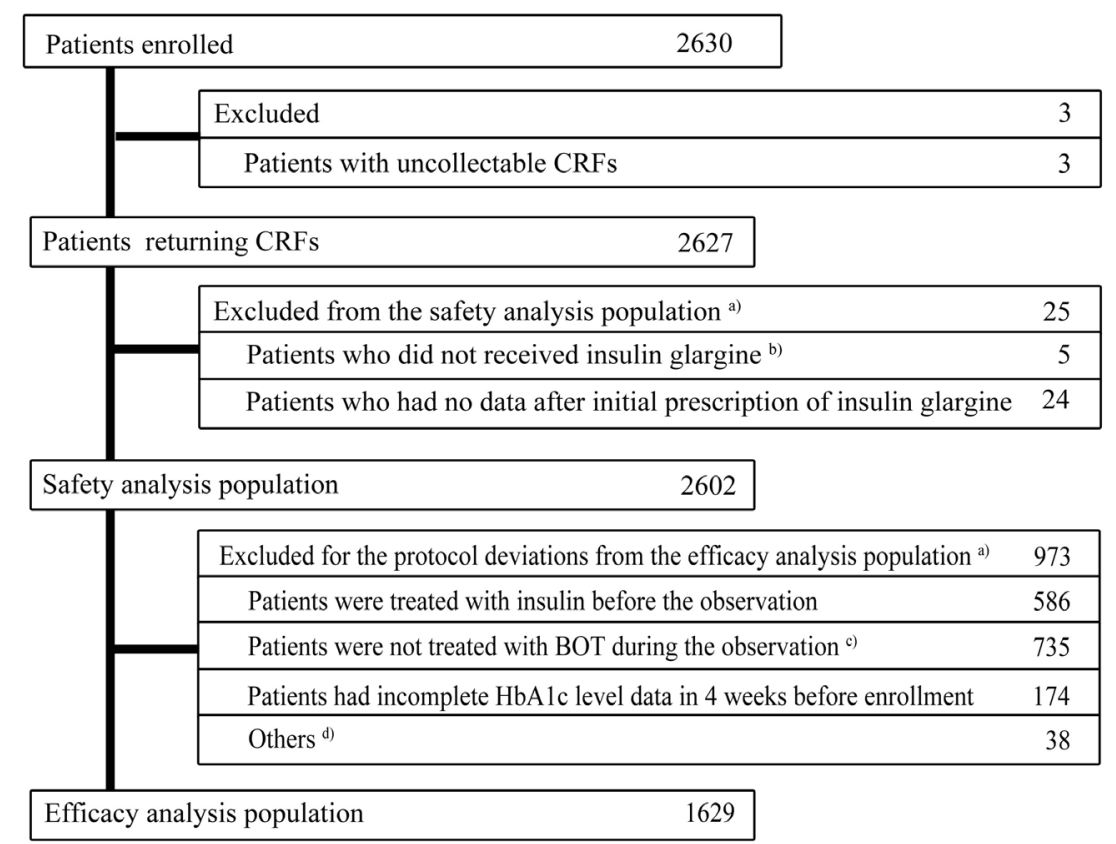

a) The number of patients overlapped between each reason; b) The number included 1 patient with double registration; c) The patients who received no OADs at the baseline or who treated with the additional insulin others during the observation; d) The patients whose clinics or hospitals had a incomplete contract including the period etc. and who had missing data of the administration of insulin others.

\section{Figure 1. Disposition of patients in ALOHA 2 study.}


Table 1. Baseline characteristics.

Number of patients (\%)

\begin{tabular}{|c|c|c|}
\hline & \multicolumn{2}{|c|}{ Number of patients (\%) } \\
\hline & Safety analysis population $(n=2602)$ & Efficacy analysis population $(n=1629)$ \\
\hline \multicolumn{3}{|l|}{ Sex } \\
\hline Male & $1566(60.2)$ & $1022(62.7)$ \\
\hline Female & $1036(39.8)$ & 607 (37.3) \\
\hline Age (mean, years) ${ }^{\mathrm{a}}$ & 62.6 & 61.8 \\
\hline Weight (mean, kg) & 64.6 & 65.7 \\
\hline BMI (mean, kg/m²) & 24.8 & 25.0 \\
\hline \multicolumn{3}{|l|}{ Duration of diabetes (years) ${ }^{\mathrm{a}}$} \\
\hline$<1$ & $70(2.7)$ & $49(3.0)$ \\
\hline$\geq 1,<5$ & $315(12.1)$ & $212(13.0)$ \\
\hline$\geq 5,<10$ & $448(17.2)$ & 305 (18.7) \\
\hline$\geq 10,<15$ & $493(19.0)$ & 318 (19.5) \\
\hline$\geq 15$ & $720(27.7)$ & 389 (23.9) \\
\hline Unknown/not specified & $556(21.4)$ & 356 (21.9) \\
\hline \multicolumn{3}{|l|}{ Complications } \\
\hline Diabetic nephropathy & $624(24.0)$ & $367(22.5)$ \\
\hline Diabetic retinopathy & $412(15.8)$ & $237(14.6)$ \\
\hline Diabetic neuropathy & $430(16.5)$ & $243(14.9)$ \\
\hline Hypertension & $1311(50.4)$ & $778(47.8)$ \\
\hline Dyslipidaemia & 1376 (52.9) & 846 (51.9) \\
\hline Ischemic heart disease & $179(6.9)$ & $91(5.6)$ \\
\hline Ischemic cerebrovascular disease & $129(5.0)$ & $71(4.4)$ \\
\hline Peripheral arterial occlusive disease & $105(4.0)$ & $56(3.4)$ \\
\hline \multicolumn{3}{|l|}{ Laboratory values ${ }^{\mathrm{c})}$} \\
\hline HbA1c (mean, \%) ${ }^{\mathrm{b})}$ & 9.35 & 9.58 \\
\hline FPG (mean, mg/dL) ${ }^{b)}$ & 198.1 & 204.6 \\
\hline 2h-PPG (mean, mg/dL) ${ }^{\mathrm{b})}$ & 263.4 & 272.8 \\
\hline Fasting plasma CPR (mean, ng/mL) & 1.97 & 2.14 \\
\hline e-GFR (mean, mL/min/1.73 m²) & 79.0 & 81.2 \\
\hline \multicolumn{3}{|l|}{ Treatment regimen } \\
\hline \multicolumn{3}{|l|}{ Anti-diabetes drugs regimen at baseline } \\
\hline Basal-bolus $\pm \mathrm{OAD}^{\mathrm{b})}$ & $177(6.8)$ & $0(0.0)$ \\
\hline Basal only & $93(3.6)$ & $0(0.0)$ \\
\hline BOT & $2270(87.2)$ & $1629(100.0)$ \\
\hline Number of OAD: 1 & $744(28.6)$ & 477 (29.3) \\
\hline Number of OAD: 2 & $786(30.2)$ & 566 (34.8) \\
\hline Number of OAD: 3 & $558(21.5)$ & 438 (26.9) \\
\hline Number of OAD: $\geq 4$ & $182(7.0)$ & $148(9.1)$ \\
\hline Others & $62(2.4)$ & $0(0.0)$ \\
\hline
\end{tabular}

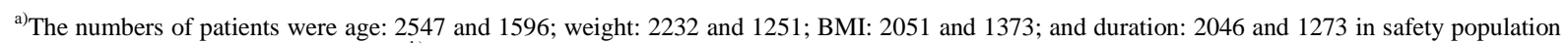

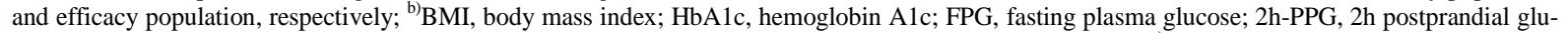
cose; CPR, C-peptide reactivity; e-GFR, estimated glomerular filtration rate; OAD, oral anti-diabetic drugs; ${ }^{\mathrm{c}}$ The numbers of patients were HbA1c levels: 2437 and 1629; FPG levels: 935 and 621; 2h-PPG levels: 615 and 416; Fasting plasma CPR: 204 and 125; e-GFR: 1644 and 1059 in safety population and efficacy population, respectively. 
body mass index (BMI) prior to treatment were $64.6 \mathrm{~kg}$ and $24.8 \mathrm{~kg} / \mathrm{m}^{2}$, respectively. As for complications, $24.0 \%$ had diabetic nephropathy, $15.8 \%$ had diabetic retinopathy, and $16.5 \%$ had diabetic neuropathy. Patients with $\geq 5$ years of diabetic duration accounted for 63.8\%. The mean HbAlc, FPG and 2 hour-PPG levels were 9.35\%, $198.1 \mathrm{mg} / \mathrm{dL}$ and $263.4 \mathrm{mg} / \mathrm{dL}$, respectively. At baseline, $28.6 \%, 30.2 \%, 21.5 \%$ and $7.0 \%$ of the patients used 1 , 2, 3 and $\geq 4$ OADs, respectively. The characteristics and baseline values in the efficacy analysis population were similar to those of the safety analysis population.

\subsection{Concomitant Drugs with Insulin Glargine}

The percent of concomitant OADs during the study period in the safety and efficacy analysis populations is shown in Table 2. SUs were commonly used as concomitant OADs, while DPP-4 inhibitors were the second most prescribed in both populations. In the 1629 BOT patients, the ratios of patients were $70.1 \%$ at baseline and 71.5\% during study in SU and 54.3\% at baseline and 60.7\% during study in DPP-4 inhibitors. The administration rate (\%) of combination OADs in the ALOHA 2 Study was similar to that in previous ALOHA Study; however, DPP-4 inhibitors were newly added to BOT in the ALOHA 2 Study.

\subsection{Doses of Insulin Glargine and Compliance Status of Therapies}

In the efficacy analysis population, treated with BOT and having had no pre-treatment insulin, the mean doses of insulin glargine in the initial and final administration were $6.3 \mathrm{U} /$ day and $9.8 \mathrm{U} /$ day, respectively (Table 3). Most of patients $(n=1585,97.3 \%)$ received a mean dose of insulin glargine of $20 \mathrm{U} /$ day or less. Among them, 1482 patients (91.0\%) were reported as good compliance of the insulin glargine treatment. In addition, 463 (28.4\%) and 556 (34.1\%) patients were reported as good compliance as directed by physicians in exercise and diet therapies, respectively (Table 4). The safety analysis population had higher mean dose than the efficacy analysis population because the safety population included the patients who treated with other insulin products before the observation (data not shown).

Table 2. Oral anti-diabetic drugs used concomitantly with insulin glargine.

\begin{tabular}{|c|c|c|}
\hline \multirow[b]{2}{*}{ Concomitant drugs } & \multicolumn{2}{|c|}{ Number of patients (\%) } \\
\hline & $\begin{array}{l}\text { Safety analysis population } \\
(\mathrm{n}=2602)^{\mathrm{a})}\end{array}$ & $\begin{array}{l}\text { Efficacy analysis population } \\
\qquad(\mathrm{n}=1629)\end{array}$ \\
\hline \multicolumn{3}{|l|}{ At baseline } \\
\hline DPP-4 inhibitors ${ }^{\mathrm{b})}$ & $1342(51.6)$ & $884(54.3)$ \\
\hline Sulfonylureas & $1460(56.1)$ & $1142(70.1)$ \\
\hline Biguanides & $1101(42.3)$ & 737 (45.2) \\
\hline Thiazolidinediones & $327(12.6)$ & $249(15.3)$ \\
\hline$\alpha$-glucosidase inhibitors & $680(26.1)$ & $433(26.6)$ \\
\hline Insulin secretagogues & $124(4.8)$ & $74(4.5)$ \\
\hline \multicolumn{3}{|l|}{ During study period } \\
\hline DPP-4 inhibitors ${ }^{\mathrm{b})}$ & 1545 (59.4) & $988(60.7)$ \\
\hline Sulfonylureas & $1510(58.0)$ & $1164(71.5)$ \\
\hline Biguanides & 1205 (46.3) & $792(48.6)$ \\
\hline Thiazolidinediones & 352 (13.5) & 269 (16.5) \\
\hline$\alpha$-glucosidase inhibitors & $780(30.0)$ & $490(30.1)$ \\
\hline Insulin secretagogues & $178(6.8)$ & 109 (6.7) \\
\hline
\end{tabular}

a) The DPP-4 inhibitors, sulfonylureas, biguanides, thiazolidinediones $\alpha$-glucosidase inhibitors and insulin secretagogues data at baseline were unavailable for 4, 6, 6, 8, 6 and 8 patients, respectively. The DPP-4 inhibitors, Sulfonylureas, Biguanides, Thiazolidinediones, $\alpha$-glucosidase inhibitors

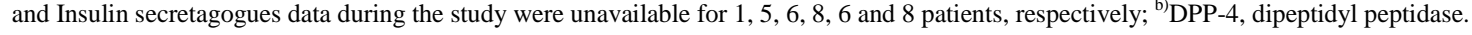




\subsection{Adverse Drug Reactions}

Of 2602 patients in the safety analysis population, 161 patients (6.19\%) experienced 175 cases of adverse drug reactions (Table 5). The main adverse drug reaction was hypoglycaemia ( $\mathrm{n}=140$ patients, $5.38 \%$ ), which included severe hypoglycaemia $(n=11)$, documented symptomatic hypoglycaemia $(n=54)$ and nocturnal hypoglycaemia $(n=14)$. They occurred at the following incidence rates (episodes per patient-year): all hypoglycaemia, 0.273; severe, 0.019;

Table 3. Time course and mean change in the insulin glargine dosage.

\begin{tabular}{lcc} 
& & Efficacy analysis population ( $\mathrm{n}=1629)$ \\
\cline { 2 - 3 } \multicolumn{1}{c}{ Observed period } & Number of patients & Mean insulin glargine dosage (U/day) \\
\hline Baseline & 1627 & 6.3 \\
4 week & 1612 & 7.6 \\
8 week & 1570 & 8.5 \\
12 week & 1534 & 9.0 \\
16 week & 1489 & 9.4 \\
20 week & 1445 & 9.8 \\
24 week & 1419 & 10.1 \\
LOCF $^{\text {a) }}$ & 1627 & 9.8 \\
\hline
\end{tabular}

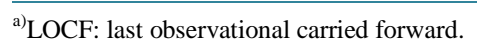

Table 4. Compliance with insulin glargine treatment, exercise therapy and diet therapy.

\begin{tabular}{|c|c|}
\hline \multirow[b]{2}{*}{ Evaluation items } & Number of patients (\%) \\
\hline & Efficacy analysis population $(\mathrm{n}=1629)$ \\
\hline \multicolumn{2}{|l|}{ Compliance status of insulin glargine treatment ${ }^{\mathrm{a})}$} \\
\hline Good compliance & $1482(91.0)$ \\
\hline Poor compliance & $121(7.4)$ \\
\hline Non-compliance & $24(1.5)$ \\
\hline Unknown/not specified & $2(0.1)$ \\
\hline \multicolumn{2}{|l|}{ Compliance status of exercise therapy } \\
\hline No direction & $373(22.9)$ \\
\hline Good compliance & $463(28.4)$ \\
\hline Poor compliance & $532(32.7)$ \\
\hline Non-compliance & $260(16.0)$ \\
\hline Unknown/not specified & $1(0.1)$ \\
\hline \multicolumn{2}{|l|}{ Compliance status of diet therapy } \\
\hline No direction & $113(6.9)$ \\
\hline Good compliance & $556(34.1)$ \\
\hline Poor compliance & 699 (42.9) \\
\hline Non-compliance & $260(16.0)$ \\
\hline Unknown/not specified & $1(0.1)$ \\
\hline
\end{tabular}

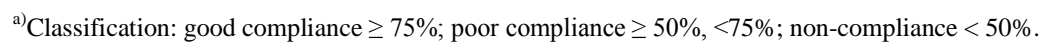


Table 5. Incidence of adverse drug reactions.

\begin{tabular}{|c|c|c|}
\hline & $\begin{array}{l}\text { Safety analysis population } \\
\qquad(\mathrm{n}=2602)\end{array}$ & $\begin{array}{l}\text { Efficacy analysis population } \\
(\mathrm{n}=1629)\end{array}$ \\
\hline Number of patients with adverse drug reactions & 161 & 103 \\
\hline Number of cases of adverse drug reactions & 175 & 114 \\
\hline Incidence (\%) of adverse drug reactions & $6.19 \%$ & $6.32 \%$ \\
\hline Types of adverse drug reactions & \multicolumn{2}{|c|}{ Incidence of adverse drug reactions by type Number of patients (\%) } \\
\hline Metabolism and nutrition disorders & - & - \\
\hline Hypoglycaemia ${ }^{\text {a) }}$ & $140(5.38)$ & $90(5.52)$ \\
\hline Severe hypoglycaemia & $11(0.42)$ & $7(0.43)$ \\
\hline Documented symptomatic hypoglycaemia & 54 (2.08) & $35(2.15)$ \\
\hline Nocturnal hypoglycaemia & $14(0.54)$ & $6(0.37)$ \\
\hline Other hypoglycaemia & $91(3.50)$ & $58(3.56)$ \\
\hline Diabetes mellitus inadequate control & $1(0.04)$ & $0(0.00)$ \\
\hline Nervous system disorders & - & - \\
\hline Diabetic neuropathy & $2(0.08)$ & $2(0.12)$ \\
\hline Eye disorders & $1(0.04)$ & $1(0.06)$ \\
\hline Diabetic retinopathy & $1(0.04)$ & $1(0.06)$ \\
\hline Gastrointestinal disorders & $2(0.08)$ & $2(0.12)$ \\
\hline Diarrhea* & $1(0.04)$ & $1(0.06)$ \\
\hline Gastritis* $^{*}$ & $1(0.04)$ & $1(0.06)$ \\
\hline Hepatobiliary disorders & $2(0.08)$ & $1(0.06)$ \\
\hline Hepatic function disorder & $2(0.08)$ & $1(0.06)$ \\
\hline Skin and subcutaneous tissue disorders & $3(0.12)$ & $2(0.12)$ \\
\hline Eczema & $1(0.04)$ & $1(0.06)$ \\
\hline Rash & $1(0.04)$ & $1(0.06)$ \\
\hline Pruritus generalised & $1(0.04)$ & $0(0.00)$ \\
\hline Renal and urinary disorder & $1(0.04)$ & $0(0.00)$ \\
\hline Dysuria* & $1(0.04)$ & $0(0.00)$ \\
\hline General disorders and administration site conditions & $9(0.35)$ & $6(0.37)$ \\
\hline Death $^{*}$ & $1(0.04)$ & $1(0.06)$ \\
\hline Hunger ${ }^{*}$ & $1(0.04)$ & $1(0.06)$ \\
\hline Oedema & $1(0.04)$ & $1(0.06)$ \\
\hline Injection site erythema & $2(0.08)$ & $2(0.12)$ \\
\hline Injection site induration & $1(0.04)$ & $1(0.06)$ \\
\hline Injection site pain & $1(0.04)$ & $0(0.00)$ \\
\hline Injection site pruritus & $2(0.08)$ & $1(0.06)$ \\
\hline Injection site rash & $1(0.04)$ & $1(0.06)$ \\
\hline Injection site swelling & $1(0.04)$ & $1(0.06)$ \\
\hline Injection site reaction & $1(0.04)$ & $0(0.00)$ \\
\hline Laboratory tests & $9(0.35)$ & $5(0.31)$ \\
\hline Alanine aminotransferase increased & $1(0.04)$ & $1(0.06)$ \\
\hline Aspartate aminotransferase increased & $1(0.04)$ & $1(0.06)$ \\
\hline Blood glucose level increased & $3(0.12)$ & $1(0.06)$ \\
\hline Blood pressure increased ${ }^{*}$ & $1(0.04)$ & $1(0.06)$ \\
\hline HbA1c level increased ${ }^{\mathrm{b})}$ & $1(0.04)$ & $1(0.06)$ \\
\hline Weight increased ${ }^{*}$ & $1(0.04)$ & $0(0.00)$ \\
\hline Anti-insulin antibody positive ${ }^{*}$ & $2(0.08)$ & $1(0.06)$ \\
\hline
\end{tabular}

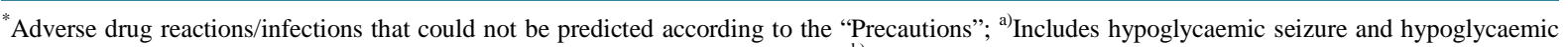

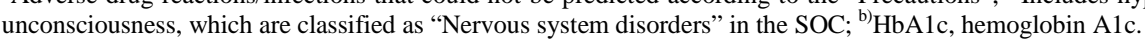

documented symptomatic, 0.099; and nocturnal, 0.023. Serious adverse drug reactions are presented in Table 6. In 
Table 6. Incidence of serious adverse drug reactions.

\begin{tabular}{|c|c|c|}
\hline & Safety analysis population $(n=2602)$ & Efficacy analysis population $(n=1629)$ \\
\hline Number of patients & 2602 & 1629 \\
\hline Number of patients with adverse drug reactions & 14 & 8 \\
\hline Number of cases of adverse drug reactions & 15 & 9 \\
\hline Incidence (\%) of adverse drug reactions & $0.54 \%$ & $0.49 \%$ \\
\hline Types of adverse drug reactions & \multicolumn{2}{|c|}{ Incidence of serious adverse drug reactions by type number of patients (\%) } \\
\hline Metabolism and nutrition disorders & $9(0.35)$ & $4(0.25)$ \\
\hline Inadequate glycaemic control & $1(0.04)$ & $0(0.00)$ \\
\hline Hypoglycaemia & $8(0.31)$ & $4(0.25)$ \\
\hline Nervous system disorders & $1(0.04)$ & $1(0.06)$ \\
\hline Hypoglycaemic seizure & $1(0.04)$ & $1(0.06)$ \\
\hline Hypoglycaemic unconsciousness & $1(0.04)$ & $1(0.06)$ \\
\hline Eye disorders & $1(0.04)$ & $1(0.06)$ \\
\hline Diabetic retinopathy & $1(0.04)$ & $1(0.06)$ \\
\hline $\begin{array}{l}\text { General disorders and administration site } \\
\text { conditions }\end{array}$ & $1(0.04)$ & $1(0.06)$ \\
\hline Death $^{*}$ & $1(0.04)$ & $1(0.06)$ \\
\hline Laboratory tests & $2(0.08)$ & $1(0.06)$ \\
\hline Blood glucose level increased & $2(0.08)$ & $1(0.06)$ \\
\hline
\end{tabular}

"Adverse drug reactions/infections that could not be predicted according to the "Precautions".

14 patients, 15 cases of serious adverse drug reactions were reported, including serious hypoglycaemia $(n=8)$, hypoglycaemic seizure $(n=1)$ and hypoglycaemic unconsciousness $(n=1)$. A patient with diabetes mellitus inadequate control was reported as serious due to poor glycaemic control and inpatient diabetes education.

The incidences of adverse drug reaction in the efficacy analysis population were similar to those in the safety analysis population.

There were 2 fatal cases reported in the surveillance and they were reported as the events of death and hypoglycaemia. The patient with "death" for which the causative events were not identified clearly, was reported later from the patient's family to the attending physician. The patient was 84 years old and the duration of diabetes was 32 years at the baseline. As for another hypoglycaemia case, the attending physician reported that the patient's family noticed the death of the patient and the relationship with hypoglycaemia could not be denied. The patient was 82 years old and the diabetes duration was 39.5 years at the baseline.

In the major cardiovascular events, non-fatal stroke $(n=3,0.12 \%)$ and cardiovascular death $(n=2,0.08 \%)$ were observed for the observation period of 24 week. These patients had no hypoglycaemic events during the study.

\subsection{Hypoglycaemia Incidence According to Patient Characteristics in BOT Patients}

As mentioned above, the major adverse drug reaction was hypoglycaemia which was of the most concern in the insulin therapy. Using the 1629 patients treated with a BOT regimen during the study period and did not have pre-treated insulins, patient characteristics (mean dose, timing of administration, types of concomitant OADs, baseline HbA1c level, etc.) that might have influenced the occurrence of hypoglycaemia while being treated with a BOT regimen were investigated.

The incidences of hypoglycaemia by baseline characteristics are shown in Table 7. Following characteristics significantly associated with higher risk for hypoglycaemia; female gender, renal function disorder, dyslipidaemia as complications, mean dose of insulin glargine, concomitant SUs, concomitant thiazolidinediones, high 
Table 7. Incidence of hypoglycaemia by patient characteristics in the efficacy analysis population.

\begin{tabular}{|c|c|c|c|}
\hline & \multirow[b]{2}{*}{$\begin{array}{l}\text { Total number of } \\
\text { patients }\end{array}$} & \multicolumn{2}{|c|}{ Incidence of hypoglycaemia } \\
\hline & & $\begin{array}{l}\% \text { of patients with } \\
\text { hypoglycaemia }\end{array}$ & Analysis ${ }^{\mathrm{a}) \mathrm{b}}$ \\
\hline Analysis population & 1629 & 5.52 & - \\
\hline \multicolumn{4}{|l|}{ Sex } \\
\hline Male & 1022 & 4.40 & $\mathrm{p}=0.0132^{*}$ \\
\hline Female & 607 & 7.41 & \\
\hline \multicolumn{4}{|l|}{ Age (years) } \\
\hline$<20$ & 0 & - & $\mathrm{p}=0.0726$ n.s. \\
\hline$\geq 20,<30$ & 11 & 0.00 & \\
\hline$\geq 30,<40$ & 65 & 4.62 & \\
\hline$\geq 40,<50$ & 197 & 4.06 & \\
\hline$\geq 50,<60$ & 352 & 4.26 & \\
\hline$\geq 60,<70$ & 506 & 5.73 & \\
\hline$\geq 70,<80$ & 363 & 6.61 & \\
\hline$\geq 80$ & 102 & 6.86 & \\
\hline Unknown/not specified & 33 & 12.1 & - \\
\hline \multicolumn{4}{|l|}{ Age (years, elderly patients) } \\
\hline$<65$ & 903 & 4.54 & $\mathrm{p}=0.0938$ n.s. \\
\hline$\geq 65$ & 693 & 6.49 & \\
\hline Unknown/not specified & 33 & 12.1 & - \\
\hline \multicolumn{4}{|l|}{ Duration of diabetes (years) } \\
\hline$<1$ & 49 & 4.08 & $\mathrm{p}=0.0542$ n.s. \\
\hline$\geq 1,<5$ & 212 & 5.19 & \\
\hline$\geq 5,<10$ & 305 & 3.93 & \\
\hline$\geq 10,<15$ & 318 & 6.92 & \\
\hline$\geq 15$ & 389 & 7.71 & \\
\hline Unknown/not specified & 356 & 3.65 & - \\
\hline \multicolumn{4}{|l|}{ Complications } \\
\hline \multicolumn{4}{|l|}{ Hepatic function disorder } \\
\hline Absent & 1313 & 5.41 & $\mathrm{p}=0.6809$ n.s. \\
\hline & 316 & 6.01 & \\
\hline \multicolumn{4}{|l|}{$\begin{array}{l}\text { Present } \\
\text { Renal function disorder }\end{array}$} \\
\hline Absent & 1251 & 4.88 & $\mathrm{p}=0.0404^{*}$ \\
\hline Present & 378 & 7.67 & \\
\hline \multicolumn{4}{|l|}{ Diabetic nephropathy } \\
\hline Absent & 1262 & 4.91 & $p=0.0513$ n.s. \\
\hline Present & 367 & 7.63 & \\
\hline \multicolumn{4}{|l|}{ Diabetic retinopathy } \\
\hline Absent & 1392 & 5.17 & $\mathrm{p}=0.1642$ n.s. \\
\hline Present & 237 & 7.59 & \\
\hline \multicolumn{4}{|l|}{ Diabetic neuropathy } \\
\hline Absent & 1386 & 5.05 & $\mathrm{p}=0.0658$ n.s. \\
\hline Present & 243 & 8.23 & \\
\hline \multicolumn{4}{|l|}{ Hypertension } \\
\hline Absent & 851 & 4.94 & $\mathrm{p}=0.2801$ n.s. \\
\hline Present & 778 & 6.17 & \\
\hline \multicolumn{4}{|l|}{ Dyslipidaemia } \\
\hline Absent & 783 & 3.58 & $\mathrm{p}=0.0010^{* *}$ \\
\hline Present & 846 & 7.33 & \\
\hline \multicolumn{4}{|c|}{ Dose and the administration time of insulin glargine } \\
\hline \multicolumn{4}{|c|}{ Mean dose of insulin glargine (unit/day) } \\
\hline$<5$ & 302 & 9.60 & $\mathrm{p}=0.0004^{* * *}$ \\
\hline$\geq 5,<10$ & 832 & 5.41 & \\
\hline$\geq 10,<15$ & 358 & 3.35 & \\
\hline$\geq 15,<20$ & 93 & 4.30 & \\
\hline$\geq 20,<30$ & 38 & 0.00 & \\
\hline$\geq 30,<40$ & 4 & 0.00 & \\
\hline$\geq 40$ & 0 & - & \\
\hline Unknown/not specified & 2 & 0.00 & - \\
\hline
\end{tabular}




\section{Continued}

Mean insulin glargine per day (unit/kg of actual weight)

$\geq 0.05,<0.1$

$\geq 0.1,<0.2$

$\geq 0.2,<0.3$

$\geq 0.3,<0.4$

$\geq 0.4,<0.5$

$\geq 0.5$

Unknown/not specified

Administration time of insulin glargine at baseline

Once daily

Morning

Day time

Night

Before bedtime

Twice daily

Morning and night

Morning and before bedtime

Unknown/not specified

Administration time of insulin glargine at $\mathrm{LOCF}^{\mathrm{c}}$

Once daily

Morning

Day time

Night

Before bedtime

Twice daily

Morning and night

Morning and before bedtime

Unknown/not specified

Concomitant $\mathrm{OADs}^{\mathrm{c}}$

DPP-4 inhibitors ${ }^{\mathrm{c})}$

Absent

Present

Sulfonylureas

Absent

Present

Absent

Present

Thiazolidinediones

Absent

Present

$\alpha$-glucosidase inhibitors

Absent

Present

Insulin secretagogues

Absent

Present

Number of concomitant OADs at baseline ${ }^{\text {c) }}$

1

2

3

$\geq 4$
50

641

988

465

1164

837

792

1139

6.00

7.74

4.70

3.66

7.69

0.00

3.23

739

6.09

2.94

6.22

4.74

0.00

0.00

6.07

0.00

7.05

4.51

0.00

12.5

0.00

5.77

5.36

3.01

6.53

5.62

5.43

4.93

8.55

5.09

6.53

5.66

3.67

109

3.77

5.83

6.85

6.08 $p=0.0733$ n.s.

$\mathrm{p}=0.6830$ n.s.

$\mathrm{p}=0.3121$ n.s.

$p=0.7399$ n.s.

$\mathrm{p}=0.0039^{* *}$

$\mathrm{p}=0.9138$ n.s.

$\mathrm{p}=0.0271^{*}$

$p=0.2395$ n.s.

$\mathrm{p}=0.5152$ n.s.

$p=0.0709$ n.s. 


\begin{tabular}{|c|c|c|c|}
\hline \multicolumn{4}{|l|}{ Continued } \\
\hline \multicolumn{4}{|c|}{ Number of concomitant OADs at LOCF ${ }^{c}$} \\
\hline 1 & 424 & 3.77 & \multirow[t]{4}{*}{$\mathrm{p}=0.0647$ n.s. } \\
\hline 2 & 611 & 5.40 & \\
\hline 3 & 433 & 7.16 & \\
\hline$\geq 4$ & 137 & 5.84 & \\
\hline \multicolumn{4}{|l|}{ Laboratory values } \\
\hline \multicolumn{4}{|l|}{ HbA1c (\%) at baseline ${ }^{c}$} \\
\hline$<6.5$ & 4 & 0.00 & \multirow[t]{8}{*}{$\mathrm{p}=0.1515$ n.s. } \\
\hline$\geq 6.5,<7.5$ & 123 & 8.94 & \\
\hline$\geq 7.5,<8.5$ & 343 & 6.71 & \\
\hline$\geq 8.5,<9.5$ & 420 & 5.00 & \\
\hline$\geq 9.5,<10.5$ & 308 & 3.90 & \\
\hline$\geq 10.5,<11.5$ & 205 & 6.34 & \\
\hline$\geq 11.5,<12.5$ & 104 & 3.85 & \\
\hline$\geq 12.5$ & 122 & 4.92 & \\
\hline \multicolumn{4}{|l|}{ FPG (mg/dL) at baseline ${ }^{\mathrm{c})}$} \\
\hline$<80$ & 4 & 0.00 & \multirow[t]{5}{*}{$\mathrm{p}=0.0277 *$} \\
\hline$\geq 80,<110$ & 22 & 0.00 & \\
\hline$\geq 110,<130$ & 46 & 2.17 & \\
\hline$\geq 130,<160$ & 112 & 2.68 & \\
\hline$\geq 160$ & 437 & 6.64 & \\
\hline Unknown/not specified & 1008 & 5.65 & - \\
\hline \multicolumn{4}{|c|}{ Change in HbA1c from baseline to the endpoint (\%) } \\
\hline$<0.5$ & 417 & 5.28 & \multirow[t]{4}{*}{$\mathrm{p}=0.4450$ n.s. } \\
\hline$\geq 0.5,<1$ & 225 & 5.33 & \\
\hline$\geq 1,<2$ & 394 & 4.82 & \\
\hline$\geq 2$ & 484 & 6.61 & \\
\hline Unknown/not specified & 109 & 4.59 & - \\
\hline \multicolumn{4}{|c|}{ Status of blood glucose self-monitoring } \\
\hline Absent & 575 & 4.52 & \multirow[t]{2}{*}{$p=0.2126$ n.s. } \\
\hline Present & 1053 & 6.08 & \\
\hline Frequency of self-monitoring & & & $p=0.5664$ n.s. \\
\hline Every day & 814 & 5.53 & \\
\hline 1 - 6 times/week & 184 & 7.61 & \\
\hline$<1$ time/week & 12 & 0.00 & \\
\hline Unknown/not specified & 1 & 0.00 & - \\
\hline
\end{tabular}

a) n.s.: not significant, ${ }^{*}<0.05,{ }^{* *}<0.01,{ }^{* * *}<0.001$; ${ }^{\text {b) }}$ The ratios of patients were analyzed. The analysis was conducted with Fisher's exact test, or Cochran-Armitage test; ${ }^{c}$ LOCF: last observational carried forward; OAD, oral anti-diabetic drugs; DPP-4, dipeptidyl peptidase; HbA1c, hemoglobin A1c; FPG, fasting plasma glucose.

baseline FPG.

With regard to age, the incidence of hypoglycaemia in elderly patients ( $\geq 65$ years) was higher than that in patients aged $<65$ years though not statistically significant $(p=0.0938)$. The risk for hypoglycaemia in patients with longer diabetes duration was higher but without statistical significance. The patients with diabetic complications did not have a higher incidence rate. There was no significant difference between the incidence of hypoglycaemia and the type of concomitant OADs except for SUs and thiazolidinediones or the numbers of combined OADs, or the status of self-monitoring of blood glucose. Among the OADs, SUs and thiazolidinediones showed significant differences, on the other hand, DPP-4 inhibitors did not show it. There were no significant differences in the administration timing of insulin glargine; however, the results were from all hypoglycaemia including daytime hypoglycaemia and nocturnal hypoglycaemia. With regard to nocturnal hypoglycaemia, of the 1629 BOT patients, nocturnal hypoglycaemia in 6 patients (7 events) was observed. The timings of administration when nocturnal hypoglycaemia occurred were before bedtime in 4 patients ( 5 events) and at the time of breakfast and dinner in 1 patient (1 event, each). Of the 6 patients (7 events), 1 patient ( 2 events) was reported to be in a serious condition, and excessive alcohol use was considered as one of the other possible causes of the 2 cases for this patient. As for the other 5 of the 5 patients, only 1 event was observed in each patient, and the treatment was continued after each patient experienced the event.

\subsection{Efficacy}

In the 1629 efficacy population, BOT with insulin glargine significantly reduced HbA1c, FPG and 2 hour-PPG levels from the baseline to the endpoint with $-1.61 \%,-54.4 \mathrm{mg} / \mathrm{dL}$ and $-74.5 \mathrm{mg} / \mathrm{dL}$ ( $\mathrm{p}<0.0001$, Table 8 ). The 
mean weight increased over the study period; however the mean change was $+0.5 \mathrm{~kg}$ (Table 8).

\subsection{Effect on PROs, Patients' Satisfaction with Treatment and Patients' Self-Reported Health}

The effect of BOT with insulin glargine on patients' satisfaction with treatment according to the DTSQs and DTSQc as well as patients' self-reported health according to the EQ-5D and EQ-VAS scores is shown in Table 9.

In DTSQs, the mean treatment satisfaction score (the sum of Questions 1 and 4-8) was increased by 3.6 ( $\mathrm{p}<$ 0.0001) from the baseline to the endpoint. The scores of Questions 2 and 3 in DTSQs represent patients' satisfaction with respect to hyperglycaemia and hypoglycaemia, respectively; a higher score indicates greater perceived frequency of hyperglycaemia and hypoglycaemia. Compared to the baseline score, the mean hyperglycaemia score at the endpoint was decreased by $-1.1(\mathrm{p}<0.0001)$. The mean hypoglycaemia score was increased by $0.4(\mathrm{p}<0.0001)$.

In DTSQc, the mean treatment satisfaction score (the sum of Questions 1 and 4-8) was 9.3, on a scale from 18 (much more satisfied now) to -18 (much less satisfied now). Also, the hyperglycaemia and hypoglycaemia scores were -0.2 and -0.5 , respectively on scales ranging from 3 (much more often now) to -3 (much less often now), and these results meant that patients reported a reduced frequency of hyperglycaemia and hypoglycaemia $(\mathrm{p}<0.0001)$.

The EQ-5D index and EQ-VAS scores were significantly improved from 0.890 and 61.5 at baseline to 0.909

Table 8. Incidence of hypoglycaemia by patient characteristics in the efficacy analysis population.

\begin{tabular}{|c|c|c|c|c|c|}
\hline \multirow[b]{2}{*}{ Evaluation items } & \multirow[b]{2}{*}{ Number of patients } & \multicolumn{3}{|c|}{ Mean } & \multirow[b]{2}{*}{ Analysis $^{\mathrm{b})}$} \\
\hline & & Baseline & LOCF $^{\text {a) }}$ & (LOCF ${ }^{\mathrm{a}}$-Baseline) & \\
\hline HbA1c (\%) $)^{a)}$ & 1520 & 9.56 & 7.94 & -1.61 & $\mathrm{p}<0.0001$ \\
\hline FPG (mg/dL) $)^{a)}$ & 402 & 203.0 & 148.6 & -54.4 & $\mathrm{p}<0.0001$ \\
\hline 2h-PPG (mg/dL) $)^{\mathrm{a})}$ & 269 & 267.0 & 192.5 & -74.5 & $\mathrm{p}<0.0001$ \\
\hline Weight (kg) & 1251 & 65.7 & 66.1 & 0.5 & $\mathrm{p}<0.0001$ \\
\hline
\end{tabular}

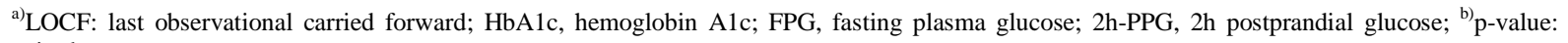
paired t-test.

Table 9. Results of patient satisfaction with treatment and patients' subjective health conditions in patients.

\begin{tabular}{|c|c|c|c|c|c|}
\hline \multirow[b]{2}{*}{ Evaluation items } & \multirow[b]{2}{*}{$\begin{array}{c}\text { Number } \\
\text { of } \\
\text { patients }\end{array}$} & \multicolumn{3}{|c|}{ Mean } & \multirow[b]{2}{*}{ Analysis ${ }^{\mathrm{b})}$} \\
\hline & & Baseline & LOCF $^{\text {a) }}$ & $\left(\mathrm{LOCF}^{\mathrm{a}}\right.$-Baseline $)$ & \\
\hline \multicolumn{6}{|l|}{ DTSQs $^{\mathrm{a})}$} \\
\hline Treatment satisfaction (Sum of Questions 1, 4-8) & 856 & 21.9 & 25.5 & 3.6 & $\mathrm{p}<0.0001$ \\
\hline Perceived frequency of hyperglycaemia (Question 2) & 890 & 3.9 & 2.7 & -1.1 & $\mathrm{p}<0.0001$ \\
\hline Perceived frequency of hypoglycaemia (Question 3) & 884 & 1.0 & 1.4 & 0.4 & $\mathrm{p}<0.0001$ \\
\hline \multicolumn{6}{|l|}{ DTSQc $^{\text {a) }}$} \\
\hline Change in treatment satisfaction (Sum of Questions 1, 4-8) & 978 & - & 9.3 & - & $\mathrm{p}<0.0001$ \\
\hline Change in perceived frequency of hyperglycaemia (Question 2) & 987 & - & -0.2 & - & $\mathrm{p}<0.0001$ \\
\hline Change in perceived frequency of hypoglycaemia (Question 3) & 984 & - & -0.5 & - & $\mathrm{p}<0.0001$ \\
\hline \multicolumn{6}{|l|}{ EQ-5D ${ }^{a)}$ and EQ-VAS ${ }^{a)}$} \\
\hline EQ-5D Index score & 856 & 0.890 & 0.909 & 0.019 & $\mathrm{p}=0.0005$ \\
\hline EQ-VAS score & 879 & 61.5 & 69.4 & 7.8 & $\mathrm{p}<0.0001$ \\
\hline
\end{tabular}

a)LOCF: last observational carried forward; DTSQs and DTSQc, Diabetes Treatment Satisfaction Questionnaire, status and change editions; EQ-5D and EQ-VAS, EuroQol Health-Related Quality of Life Questionnaire and Visual Analogue Scale; b) p-value: Wilcoxon signed-rank test. 
( $p=0.0005)$ and $69.4(\mathrm{p}<0.0001)$ at the endpoint, respectively.

From these results, BOT with insulin glargine significantly improved patients' satisfaction as shown by the DTSQs and DTSQc, and also improved patients' self-reported health on the EQ-5D index and EQ-VAS scores.

\section{Discussion}

In the ALOHA 2 Study, post-marketing surveillance, the combination therapy of insulin glargine and OADs including DPP-4 inhibitors significantly reduced not only HbA1c and FPG levels but also PPG levels. The incidence of adverse drug reactions was generally low, and the major adverse drug reactions included hypoglycaemia (5.38\%; with severe hypoglycaemia, $0.42 \%)$. They occurred at the following incidence rates (episodes per patient-year): all hypoglycaemia, 0.273; severe, 0.019; documented symptomatic, 0.099; and nocturnal, 0.023, and the combination therapy was tolerated. The incidence of severe hypoglycaemia in this present study was similar to that in previous reports. The incidence of severe hypoglycaemia in insulin glargine [14] and insulin detemir [32] in patients with type 2 diabetes was $0.32 \%$ and $0.4 \%$, respectively.

The effects of insulin glargine used in BOT on glycaemic control have already been reported in several previous studies [8] [33]. In Japan, the ALOHA Study, which we conducted as a mandatory post-marketing surveillance, well described the usefulness of BOT; however, the context of the concomitant OADs had been changed from the period of this study followed by the approval of DPP-4 inhibitors [8]. Several studies have reported that the combination therapy with DPP-4 inhibitors and insulin resulted in a low incidence of hypoglycaemia and achieved good glycaemic control through the inhibition of HbA1c, FPG and PPG levels [15] [34]. Also, in the observational study with 1,483 T2DM subjects with metformin and DPP-4 inhibitors, the HbA1c and FPG levels decreased by $-1.15 \%$ and $-47.3 \mathrm{mg} / \mathrm{dL}$, respectively, with the initiation of insulin glargine during 20 weeks [14]. In the present ALOHA 2 Study, DPP-4 inhibitors were administered to approximately 60\% of the patients during the study period, and the 2 hour-PPG levels were also significantly reduced together with HbA1c and FPG levels in spite of no high mean dose of insulin glargine in 24 weeks. Furthermore, the decrease in HbA1c levels was a little larger in the present ALOHA 2 Study $(-1.61 \%)$ than in the previous ALOHA Study $(-1.43 \%)$.

In addition to the significant improvement of glycaemic control, the treatment satisfaction scores of DTSQs and DTSQc, EQ-5D index and EQ-VAS scores were improved in this study although insulin was added to oral agents. The perceived frequency of hypoglycaemia score with DTSQc was a minus score that meant lower frequency of hypoglycaemia, and had a different trend from that of DTSQs. It is possible that patients did give these contrary responses due to halo effects of being pleased with other outcomes associated with BOT or because different patients were included in the two analyses. In any case, the changes with each assessment were both small, so it was considered that the change of the frequency of hypoglycaemia was not as large as the patients' actual feeling. From the result of EQ-5D, little changes were observed throughout the study. It might be because most of the patients had "no problems" with their condition at baseline. The proportions of the patients who had "no problems" at baseline ranged from $75.3 \%$ to $94.4 \%$ in the 5 questions. However, one of the important points was that these scores were not decreased in spite of the addition of injections to oral agents; therefore, it might result in a high compliance rate of insulin glargine treatment. From these PROs results, BOT with insulin glargine was acceptable for the patients and could be a good option for diabetes.

In the assessment of risk factors for hypoglycaemia showed in Table 7, DPP-4 inhibitors and biguanides were not associated with hypoglycaemia while SUs and thiazolidinediones were associated. Although this could be potentially expressing superior safety of BOT regimen with DPP-4 inhibitors and biguanides, conclusive causal relationship cannot be referred by these analyses primarily because of not adjusting confounders. The effectiveness and safety profile of the BOT regimen with different OADs need to be analyzed in the precise secondary analysis. Similarly, we cannot suggest any other conclusive causal relationship between patient characteristics and hypoglycaemia even on the factors with statistical significance in Table 7. However, higher risk for hypoglycaemia observed with low mean dose of insulin glargine and high FPG at baseline should especially be noted. Potentially, low mean dose of insulin may have been caused by preceding event of hypoglycaemia, and high FPG may have been the representation of large blood glucose variability. These should be also addressed in secondary analyses. As to the higher risk with low mean dose, when comparing the characteristics of the patients by doses, there were tendencies that the age and duration of diabetes become younger and shorter, respectively, according to increased dosage of insulin glargine (data not shown). In Table 7, the tendency of more frequent 
hypoglycaemia was observed in the patients for whom the age and the duration of diabetes become older and longer respectively (without statistical significance), and these results also supported it. Additionally, there were no significant differences in the mean daily dose (units/day) of insulin glargine.

\section{Conclusion}

In the present ALOHA 2 Study, BOT with insulin glargine including DPP-4 inhibitors was suggested to be effective and well tolerated. In addition, it is suggested to improve the patients' satisfaction and their self-reported health in spite of the addition of injections to oral agents. From these points, BOT with insulin glargine including DPP-4 inhibitors is likely to be considered an important therapeutic option in diabetic patients. However, combination therapy needs to be continuously evaluated in clinical trials or large sample analysis mainly due to the limitations of observational study/post-marketing surveillance and because OADs with new mechanisms have recently become available.

\section{Acknowledgements}

The authors are grateful to all physicians at the hospitals and clinics attending in the ALOHA 2 Study. The authors are also grateful to the developers of the DTSQs and DTSQc, Professor Clare Bradley and Health Psychology Research Ltd. (www.healthpsychologyresearch.com), for granting us permission to use the instrument in our study. Statistical analysis was performed by EPS Corp. and editorial support was provided by Honyaku Center Inc., both under the contracts with Sanofi K.K. All named authors meet the ICMJE criteria for authorship for this manuscript, take responsibility for the integrity of the work as a whole, and have given final approval to the version to be published. Sanofi had responsibility for the study design, the statistical analysis plan and the drafting and approval of the manuscript and this study was sponsored by Sanofi K.K.

\section{Conflict of Interest}

MK, ST, YI and YS are employees of Sanofi K.K., Tokyo, Japan. Insulin glargine is marketed by Sanofi under the name Lantus.

\section{References}

[1] Inzucchi, S.E., Bergenstal, R.M., Buse, J.B., Diamant, M., Ferrannini, E., Nauck, M., et al. (2012) Management of Hyperglycaemia in Type 2 Diabetes: A Patient-Centered Approach. Position Statement of the American Diabetes Association (ADA) and the European Association for the Study of Diabetes (EASD). Diabetologia, 55, 1577-1596. http://dx.doi.org/10.1007/s00125-012-2534-0

[2] Kramer, W. (1999) New Approaches to the Treatment of Diabetes. Experimental and Clinical Endocrinology Diabetes, 107, S52-S61. http://dx.doi.org/10.1055/s-0029-1212151

[3] Heinemann, L., Linkeschova, R., Rave, K., Hompesch, B., Sedlak, M. and Heise, T. (2000) Time-Action Profile of the Long-Acting Insulin Analog Insulin Glargine (HOE901) in Comparison with Those of NPH Insulin and Placebo. Diabetes Care, 23, 644-649. http://dx.doi.org/10.2337/diacare.23.5.644

[4] Lepore, M., Pampanelli, S., Fanelli, C., Porcellati, F., Bartocci, L., Di Vincenzo, A., et al. (2000) Pharmacokinetics and Pharmacodynamics of Subcutaneous Injection of Long-Acting Human Insulin Analog Glargine, NPH Insulin and Ultralente Human Insulin and Continuous Subcutaneous Infusion of Insulin Lispro. Diabetes, 49, 2142-2148. http://dx.doi.org/10.2337/diabetes.49.12.2142

[5] Yki-Järvinen, H., Dressler, A. and Ziemen, M., HOE 901/300s Study Group (2000) Less Nocturnal Hypoglycemia and Better Post-Dinner Glucose Control with Bedtime Insulin Glargine Compared with Bedtime NPH Insulin during Insulin Combination Therapy in Type 2 Diabetes. Diabetes Care, 23, 1130-1136. http://dx.doi.org/10.2337/diacare.23.8.1130

[6] Riddle, M.C., Rosenstock, J. and Gerich, J., on Behalf of the Inslin Glargine 4002 Study Investigators (2003) The Treat-toTarget Trial: Randomized Addition of Glargine or Human NPH Insulin to Oral Therapy of Type 2 Diabetic Patients. Diabetes Care, 26, 3080-3086. http://dx.doi.org/10.2337/diacare.26.11.3080

[7] Raskin, P., Allen, E., Hollander, P., Lewin, A., Gabbay, R.A., et al., for the INITIATE Study Group (2005) Initiating Insulin Therapy in Type 2 Diabetes: A Comparison of Biphasic and Basal Insulin Analogs. Diabetes Care, 28, 260265. http://dx.doi.org/10.2337/diacare.28.2.260

[8] Ohtani, T. and Ito, T. (2011) Safety and Effectiveness of BOT (Basal Supported Oral Therapy) Using Insulin Glargine 
in Japanese Patients with Type 2 Diabetes-Results from Post-Marketing Surveillance of Insulin Glargine (ALOHA Study). Shinyaku to Rinsho (Journal of New Remedies \& Clinics), 60, 458-475.

[9] Kadowaki, T., Ohtani, T. and Odawara, M. (2012) Potential Formula for the Calculation of Starting and Incremental Insulin Glargine Doses: ALOHA Subanalysis. PLOS ONE, 7, e41358. http://dx.doi.org/10.1371/journal.pone.0041358

[10] Odawara, M., Ohtani, T. and Kadowaki, T. (2012) Dosing of Insulin Glargine to Achieve the Treatment Target in Japanese Type 2 Diabetes on a Basal Supported Oral Therapy Regimen in Real Life: ALOHA Study Subanalysis. Diabetes Technology Therapeutics, 14, 635-643. http://dx.doi.org/10.1089/dia.2011.0220

[11] Kadowaki, T., Ohtani, T. and Odawara, M. (2013) Baseline Predictive Factors for Glycemic Control in Japanese Type 2 Diabetes Patients Treated with Insulin Glargine Plus Oral Antidiabetic Drugs: ALOHA Study Subanalysis. Diabetology International, 4, 16-22. http://dx.doi.org/10.1007/s13340-012-0087-6

[12] D’Alessio, D. (2011) The Role of Dysregulated Glucagon Secretion in Type 2 Diabetes. Diabetes, Obesity and Metabolism, 13, 126-132. http://dx.doi.org/10.1111/j.1463-1326.2011.01449.x

[13] McDougall, C., McKay, G.A. and Fisher, M. (2011) Drugs for Diabetes: Part 5 DPP-4 Inhibitors. British Journal of Cardiology, 18, 130-132.

[14] Seufert, J., Pegelow, K. and Bramlage, P. (2013) Efficacy and Safety of Insulin Glargine Added to a Fixed-Dose Combination of Metformin and a Dipeptidyl Peptidase-4 Inhibitor: Results of the GOLD Observational Study. Vascular Health and Risk Management, 9, 711-717. http://dx.doi.org/10.2147/VHRM.S54362

[15] Vilsbøll, T., Rosenstock, J., Yki-Järvinen, H., Cefalu, W.T., Chen, Y., Luo, E., et al. (2010) Efficacy and Safety of Sitagliptin When Added to Insulin Therapy in Patients with Type 2 Diabetes. Diabetes, Obesity and Metabolism, 12, 167-177. http://dx.doi.org/10.1111/j.1463-1326.2009.01173.x

[16] Båvenholm, P.N. and Efendic, S. (2006) Postprandial Hyperglycaemia and Vascular Damage-The Benefits of Acarbose. Diabetes and Vascular Disease Research, 3, 72-79. http://dx.doi.org/10.3132/dvdr.2006.017

[17] Bradley, C. and Lewis, K.S. (1990) Measures of Psychological Well-Being and Treatment Satisfaction Developed from the Responses of People with Tablet-Treated Diabetes. Diabetic Medicine, 7, 445-451. http://dx.doi.org/10.1111/j.1464-5491.1990.tb01421.x

[18] Howorka, K., Pumprla, J., Schlusche, C., Wagner-Nosiska, D., Schabmann, A. and Bradley, C. (2000) Dealing with Ceiling Baseline Treatment Satisfaction Level in Patients with Diabetes under Flexible, Functional Insulin Treatment: Assessment of Improvements in Treatment Satisfaction with a New Insulin Analogue. Quality of Life Research, 9, 915-930. http://dx.doi.org/10.1023/a:1008921419108

[19] EuroQol Group (1990) EuroQol-A New Facility for the Measurement of Health-Related Quality of Life. Health Policy, 16, 199-208. http://dx.doi.org/10.1016/0168-8510(90)90421-9

[20] Sakamaki, H., Ikeda, S., Ikegami, N., Uchigata, Y., Iwamoto, Y., Origasa, H., et al. (2006) Measurement of HRQL Using EQ-5D in Patients with Type 2 Diabetes Mellitus in Japan. Value in Health, 9, 47-53. http://dx.doi.org/10.1111/j.1524-4733.2006.00080.x

[21] Nozaki, T., Morita, C., Matsubayashi, S., Ishido, K., Yokoyama, H., Kawai, K., et al. (2009) Relation between Psychosocial Variables and the Glycemic Control of Patients with Type 2 Diabetes: A Cross-Sectional and Prospective Study. BioPsychoSocial Medicine, 3, 4. http://dx.doi.org/10.1186/1751-0759-3-4

[22] Yang, W., Lv, X., Li, Q., Jia, W. and Tian, H. (2012) A Prospective Study to Optimize Insulin Treatment by Switching to Insulin Glargine in Type 2 Diabetic Patients Previously Uncontrolled on Premixed Insulin: The Optimization Study. Current Medical Research and Opinion, 28, 533-541. http://dx.doi.org/10.1185/03007995.2012.671764

[23] Kawamori, R., Kadowaki, T., Ishii, H., Iwasaki, M. and Iwamoto, Y. (2009) Efficacy and Safety of Insulin Glulisine in Japanese Patients with Type 1 Diabetes Mellitus. Diabetes, Obesity and Metabolism, 11, 891-899. http://dx.doi.org/10.1111/j.1463-1326.2009.01086.x

[24] Janssen, M.F., Lubetkin, E.I., Sekhobo, J.P. and Pickard, A.S. (2011) The Use of the EQ-5D Preference-Based Health Status Measure in Adults with Type 2 Diabetes Mellitus. Diabetic Medicine, 28, 395-413. http://dx.doi.org/10.1111/j.1464-5491.2010.03136.x

[25] Kashiwagi, A., Kasuga, M., Araki, E., Oka, Y., Hanafusa, T., Ito, H., et al. (2012) International Clinical Harmonization of Glycated Hemoglobin in Japan: From Japan Diabetes Society to National Glycohemoglobin Standardization Program Values. Journal of Diabetes Investigation, 3, 39-40. http://dx.doi.org/10.1111/j.2040-1124.2012.00207.x

[26] Bradley, C., Plowright, R., Stewart, J., Valentine, J. and Witthaus, E. (2007) The Diabetes Treatment Satisfaction Questionnaire Change Version (DTSQc) Evaluated in Insulin Glargine Trials Shows Greater Responsiveness to Improvements than the Original DTSQ. Health and Quality of Life Outcomes, 5, 57. http://dx.doi.org/10.1186/1477-7525-5-57

[27] Caire, P., Plowright, R., Conway, K. and Bradley, C. (2010) Is It Necessary to Adapt the UK English Original of the Diabetes Treatment Satisfaction Questionnaire (DTSQs) before Use in Other Countries? 2010 International Society for 
Quality of Life Research Meeting Abstracts. Quality of Life Research, 19, 63.

[28] Ishii, H., Bradley, C., Riazi, A., Barendse, S. and Yamamoto, T. (2000) The Japanese Version of the Diabetes Treatment Satisfaction Questionnaire (DTSQ): Translation and Clinical Evaluation. Journal of Clinical and Experimental Medicine, 192, 809-814.

[29] Ikegami, N., Fukuhara, S., Shimozuma, K. and Ikeda, S. (2001) Handbook of QOL Assessment for Clinical. Igaku-Shoin Ltd., Tokyo.

[30] Tsuchiya, A., Ikeda, S., Ikegami, N., Nishimura, S., Sakai, I., Fukuda, T., et al. (2002) Estimating an EQ-5D Population Value Set: The Case of Japan. Health Economics, 11, 341-353. http://dx.doi.org/10.1002/hec.673

[31] Japanese EuroQol Translation Team (1998) The Development of the Japanese EuroQol Instrument. Iryo to Shakai, 8, 109-123.

[32] Namba, M., Kaku, K., Yoshioka. N., Yamada, Y., Watada, H., Ueki, K., et al. (2012) The PREDICTIVE ${ }^{\mathrm{TM}}$ Study: A Multinational, Prospective Observational Study to Evaluate the Safety and Efficacy of Insulin Detemir Treatment in Patients with Type 1 and 2 Diabetes-Data from the Japan Cohort. Diabetology International, 3, 11-20. http://dx.doi.org/10.1007/s13340-011-0051-X

[33] Schreiber, S.A. and Haak, T. (2007) Insulin Glargine Benefits Patients with Type 2 Diabetes Inadequately Controlled on Oral Antidiabetic Treatment: An Observational Study of Everyday Practice in 12,216 Patients. Diabetes, Obesity and Metabolism, 9, 31-38. http://dx.doi.org/10.1111/j.1463-1326.2006.00593.x

[34] Kothny, W., Foley, J., Kozlovski, P., Shao, Q., Gallwitz, B. and Lukashevich, V. (2013) Improved Glycaemic Control with Vildagliptin Added to Insulin, with or without Metformin, in Patients with Type 2 Diabetes Mellitus. Diabetes, Obesity and Metabolism, 15, 252-257. http://dx.doi.org/10.1111/dom.12020 
Scientific Research Publishing (SCIRP) is one of the largest Open Access journal publishers. It is currently publishing more than 200 open access, online, peer-reviewed journals covering a wide range of academic disciplines. SCIRP serves the worldwide academic communities and contributes to the progress and application of science with its publication.

Other selected journals from SCIRP are listed as below. Submit your manuscript to us via either submit@scirp.org or Online Submission Portal.
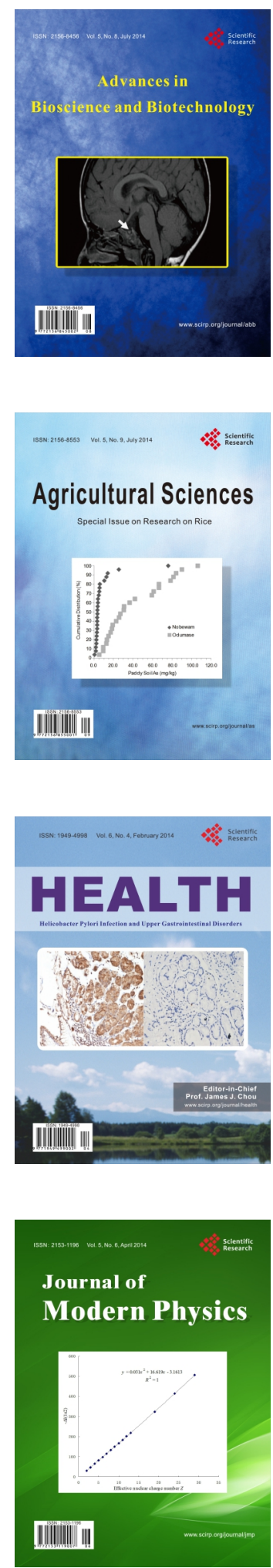
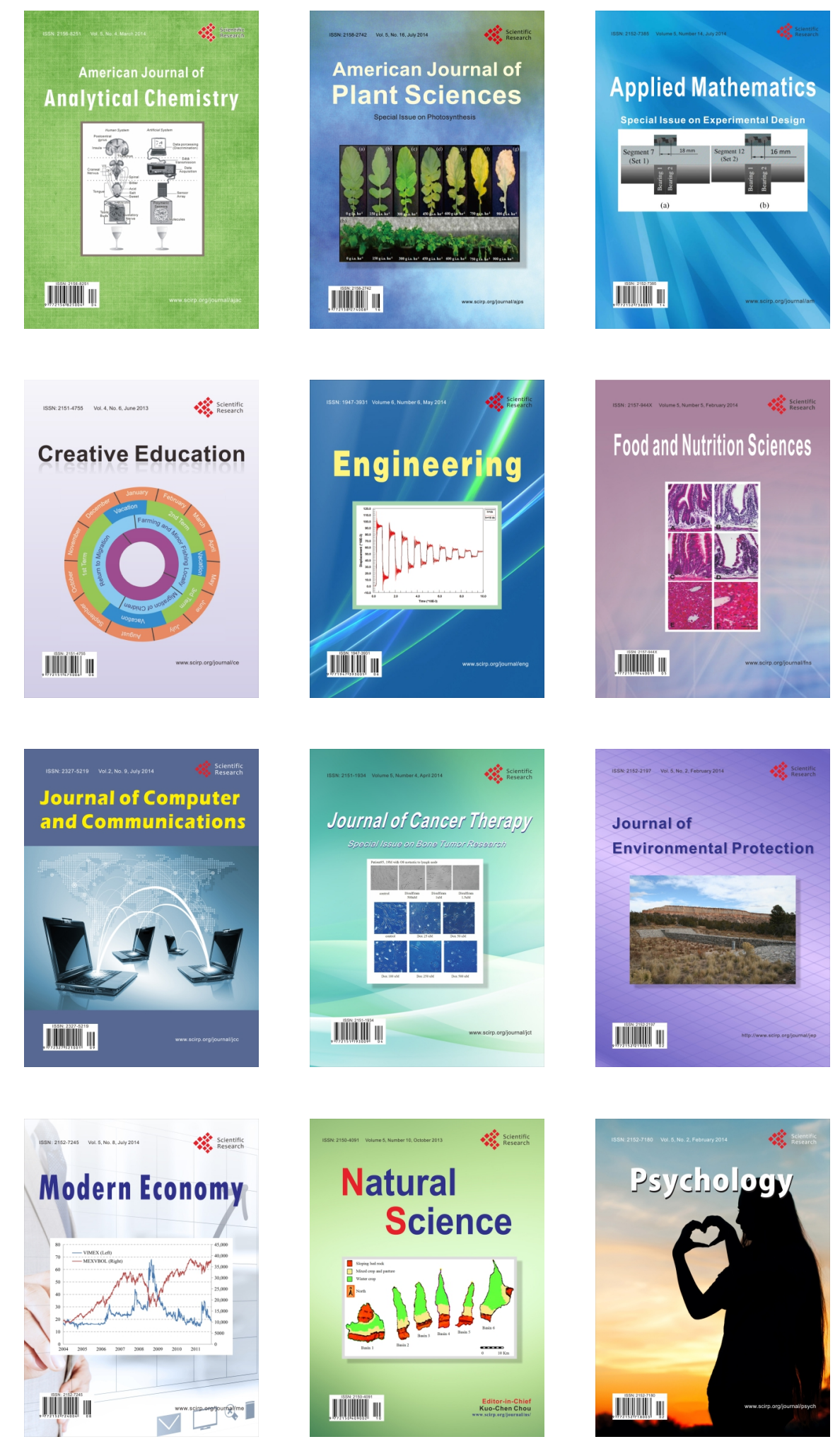